\title{
Interventions for bullous pemphigoid: An updated systematic review of randomized clinical trials
}

\author{
Ali Asilian ${ }^{1,2}$, Hoda Safaei ${ }^{1}$, Fariba Iraji ${ }^{1,2} * \mathbb{D}$, Farahnaz Fatemi Naeini ${ }^{1,2}$, Gita Faghihi ${ }^{1,2}$, Fatemeh Mokhtari ${ }^{1,2}$ \\ Received: 27 Nov 2020 \\ Published: 1 Sep 2021
}

\begin{abstract}
Background: Bullous pemphigoid (BP) is a widely recognized autoimmune blistering disease (AIBD) linked with a high incidence of morbidity and mortality. The aim of this study was to evaluate the available findings of randomizedl clinical trial studies to update interventions for Bullous pemphigoid.

Methods: This article provides an updated overview of interventions for BP. A literature search was performed using Cochrane Central Register of Clinical Trials, MEDLINE, Scopus, and Web of Science from August 2010 to December 2020. All randomized clinical trials (RCTs) were done on adults and investigated the effectiveness of administered topical or systemic medications versus placebos or controls included in the current systematic review. Three RCTs comprising 363 patients were included in the systematic review. One of the eligible studies was placebo-controlled. All of the included studies used various interventions including, methylprednisolone plus azathioprine versus methylprednisolone plus dapsone, doxycycline versus prednisolone, and intravenous immunoglobulin (IVIG).

Results: Following their potentials in disease control, no difference was observed between dapsone and azathioprine; although, dapsone had a higher corticosteroid-sparing potential. The evaluation of the effect of doxycycline in short-term blister control in comparison to corticosteroids showed that the medication was not inferior to prednisolone, although it had a higher long-term safety.

Conclusion: Therapeutic outcome of IVIG for steroid-resistant patients was satisfactory. Moreover, the effectiveness and reliability of various immunosuppressive drugs and tetracyclines are investigated by blinded RCTs for the treatment of BP.
\end{abstract}

Keywords: Bullous pemphigoid, Intervention, Treatment, Randomized controlled trials

Conflicts of Interest: None declared

Funding: Isfahan University of Medical Sciences, Isfahan, Iran

*This work has been published under CC BY-NC-SA 1.0 license.

Copyright $\odot$ Iran University of Medical Sciences

Cite this article as: Asilian A, Safaei H, Iraji F, Fatemi Naeini F, Faghihi G, Mokhtari F. Interventions for bullous pemphigoid: An updated systematic review of randomized clinical trials. Med J Islam Repub Iran. 2021 (1 Sep);35:111. https://doi.org/10.47176/mjiri.35.111

\section{Introduction}

A widely recognized autoimmune sub-epidermal blistering disease (AIBD) of the skin is Bullous pemphigoid (BP), with predominance in elders. The etiology of the disease has not been understood fully. Nevertheless, a number of factors such as drugs, radiation therapy, and neurological disorders have been proposed as risk factors for BP (1-5). In Europe an countries, the prevalence of BP fluctuates over the range of 2.5 to 43 new cases per

Corresponding author: Dr Fariba Iraji, iraji@med.mui.ac.ir

1. Department of Dermatology, School of Medicine, Isfahan University of Medical Sciences, Isfahan, Iran

2. Skin Diseases and Leishmaniasis Research Center, Isfahan University of Medical Sciences, Isfahan, Iran million annually, and it is evidlent that females are at high risk (6-10). The prevalence of BP increases with age. It has been estimated that the risk for the development of BP is about 300 -folds higher in patients aged $>90$ years as compared to patients aged $<60$ years (11).

The clinical presentation of the disease is extremely polymorphic. Generally, the initial phase of disease begins with an atypical non-bullous phase with nonspecific mani-

$\uparrow$ What is "already known" in this topic:

Bullous pemphigoid (BP) is the most common autoimmune sub-epidermal blistering disease of the skin which usually affects the elderly. The etiology of the disease has not been understood fully.

$\rightarrow$ What this article adds:

The results of the present systematic review indicated that dapsone can be used as an adjuvant therapy in the treatment of $\mathrm{BP}$ with relatively low mortality rate. 
festations. At this initial phase, patients are more prone to experience pruritus alone or combined with excoriated, eczematous, papular, or urticaria-resembling lesions. BP's initial phase possibly lasts for some months and in several patients, it remains as a sign of the disease $(12,13)$. Either on normal or erythematous skin, the characteristics of the bullous stage is the presence of tense bullae with a diameter of 1 to $3 \mathrm{~cm}$. The distribution of lesions is symmetric with predominance on the trunk, abdomen, and proximal extremities. Moreover, oral cavity involvement has been observed in $10-30 \%$ of patients $(14,15)$.

Clinical presentation, immunopathological results, and enzyme-linked immunosorbent assay (ELISA) are the basis for the diagnosis of BP. Across the basement membrane of the epidermis, direct immunofluorescence (IF) microscopy manifests linear deposition of $\operatorname{IgG}$ and/or C3. However, in blood circulation, the specific IgG autoantibodies presence is manifested by either indirect IF microscopy or ELISA (16).

Regarding the lack of published studies on the treatment of BP, numerous publications of national \& international guidelines are used as the main sources of information on the treatment of the disease (17-19). Depending on patients' comorbidities, various treatment options are used which vary from topical and systemic corticosteroids to immunosuppressive agents. As morbidity is linked with the severity of pruritis and also the existence of blisters and lesions, therefore, it is necessary to manage BP patients intensively (16).

The Cochrane review by Kirtsching et al. revised and assessed the BP interventions. The findings of the investigation demonstrated that in order to treat moderate BP, remarkably potent topical steroids are reliable and effective. Based on their outcomes, it is quite difficult to control the disease with initial doses $(>0.75 \mathrm{mg} / \mathrm{kg} /$ day $)$ of prednisolone (20). The current study was designed to systematically review recent randomized clinical trials (RCTs) on BP treatment.

\section{Methods}

\section{Literature search}

This systematic study was carried out under PRISMA recommendations (Preferred Reporting Items for Systematic Reviews and Meta-Analyses). Between August 2010 and December 2020, a systematic search of the research work was done in the below-mentioned databases: OvidMedline, PubMed, Web of Science, Scopus, and Cochrane. We used free text as well as Medical Subject Heading (MeSH) terms "Bullous Pemphigoid", "Pemphigoid", "Pemphigoids", "Prednisone", "Dehydrocortisone", "delta-Cortisone", "Rectodelt", "Prednison Hexal", "Sterapred", "Ultracorten", "Winpred", “ApoPrednisone", "Cortan", "Cortancyl", "Panafcort", "Cutason", "Decortin", "Dacortin", "Decortisyl”, "Deltasone", "Encortone", "Encorton", "Enkortolon", "Kortancyl", "Liquid Pred", "Meticorten", "Orasone", "Panasol", "Predni Tablinen", "Prednidib", "Predniment", "Prednison Acsis", "Acsis, Prednison", "Pronisone", "Sone", "Prednison Galen", "Prednisolone", "Predate", "Predonine", "Di-Adreson-F", "Di Adreson
F", "DiAdresonF", "azathioprine", “Azothioprine”, "Imurel”, "Imuran", "Immuran", "Azathioprine Sodium", "Sodium, Azathioprine”, "Azathioprine Sodium Salt", "Azathioprine Sulfate", "mycofenolate mofetil", "Mycophenolate Mofetil", "Mofetil, Mycophenolate", "Mycophenolic Acid Morpholinoethyl Ester", "Cellcept", "Mycophenolate Sodium", "Sodium Mycophenolate", "Mycophenolate, Sodium", "Myfortic", "Mycophenolate Mofetil Hydrochloride", "Mofetil Hydrochloride, Mycophenolate", "RS 61443", "RS-61443", "RS61443”, "tetracycline", "Tetrabid", "4-Epitetracycline", "4 Epitetracycline", "Topicycline", "Achromycin V", "Hostacyclin", "Tetracycline Hydrochloride", "Tetracycline Monohydrochloride", "Sustamycin", "Achromycin", "plasma exchange", "Exchange, Plasma", "Exchanges, Plasma", "Plasma Exchanges", "Hormones, Adrenal Cortex", "Adrenal Cortex Hormone", "Cortex Hormone, Adrenal", "Hormone, Adrenal Cortex", "Corticosteroids", "Corticosteroid", "Corticoids", "Corticoid", "Therapy", "treatment", or "disease management". To identify further eligible studies for inclusion in our review, the references of identified articles and reviews were also manually searched.

\section{Selection of studies}

Two independent reviewers (H.S \& A.A) screened the titles and abstracts of the searched results and excluded irrelevant publications. Full texts of remaining publications were also evaluated for inclusion in the systematic review. RCTs were considered eligible if they assessed the effectiveness of administered topical or systemic medications against placebos or controls for BP treatment in adult patients. All studies which have done on pediatrics or pregnant women were excluded. We also excluded case reports, editorials, conference reports, and review articles.

\section{Quality assessment and datia extraction}

By using a standard data collection form, two independent investigators (H.S \& A.A) extracted the data, which consists up of the name of the first author, publication date / year, name of the country where the investigation was carried out, study category, size of the sample, mean age, sample males proportion, follow up duration, description of the intervention, primary outcome, side effects, and mortality rate.

Two independent (H.S \& A.A) investigators evaluated the quality of studies that taken into account. Investigators discussed their controversies and any disagreement was resolved through discussion and re-evaluation.

\section{Results}

Figure 1 explains and summarizes the procedure of study selection. Our preliminary search provided 603 citations. After screening the titles and abstracts, 10 studies were selected due to the eligibility criteria. Finally, 3 articles were selected according to their fulltext in this update (Fig. 1). The included studies encompassed 363 participants with a mean age ranged from 65.1 to 77.7 years (2123).

The details of the studies included in the current 


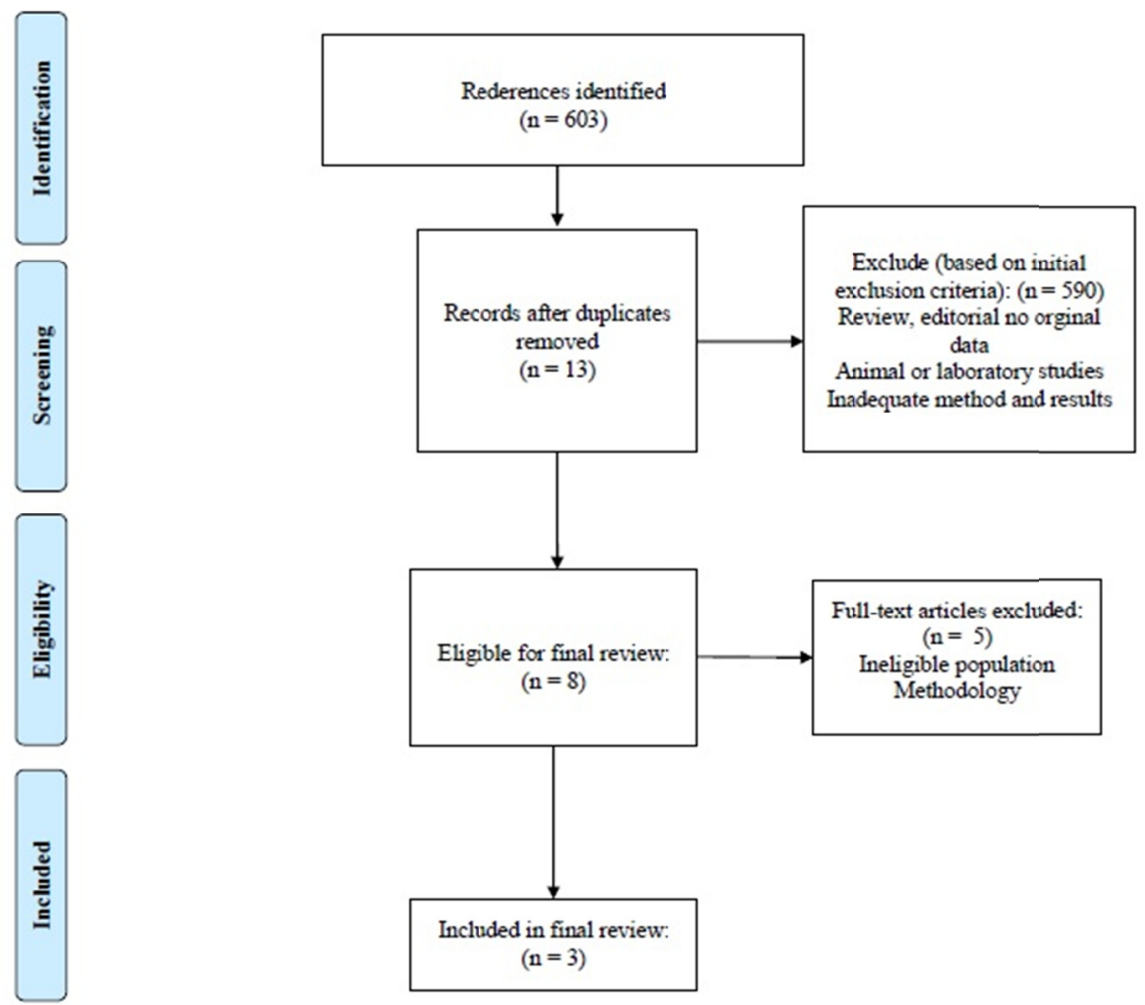

Fig. 1. PRISMA diagram of the literature search

systematic review are shown in Table 1. Only one of the eligible studies was placebo-controlled (23). All of the included studies used various interventions including, methylprednisolone plus azathioprine versus methylprednisolone plus dapsone (21), doxycycline versus prednisolone (22), and intravenous immunoglobulin (IVIG) (23).
The sample size was larger than 100 participants in one of the included studies (22) and the follow-up period varied between 1.87 to 12 months. We presented the results of each intervention separately in terms of main outcomes, relapse, side effects, and mortality rate (where applicable).

Table 1. Characteristics of the included studies

\begin{tabular}{|c|c|c|c|c|c|c|c|c|}
\hline 冚 & $\stackrel{\Xi}{\check{D}}$ & 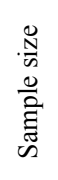 & 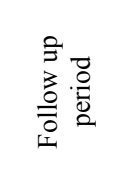 & 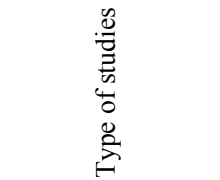 & 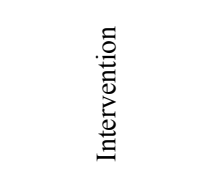 & 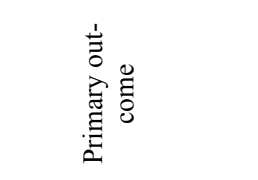 & 尝 & 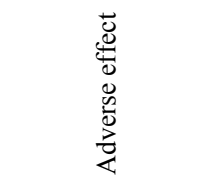 \\
\hline M. Sticherling & 2017 & 54 & 12 months & $\begin{array}{l}\text { Multicenter, } \\
\text { randomized, non- } \\
\text { blinded } \\
\text { clinical trial }\end{array}$ & $\begin{array}{l}\text { Methylpredniso- } \\
\text { lone } \\
\text { plus azathioprine } \\
\text { versus } \\
\text { methylpred } \\
\text { nisolone plus dap } \\
\text { sone }\end{array}$ & $\begin{array}{l}\text { The time until com- } \\
\text { plete tapering of } \\
\text { methylprednisolone }\end{array}$ & $\begin{array}{l}\text { Three deaths in } \\
\text { the azathioprine } \\
\text { group versus } \\
\text { one in the dap- } \\
\text { sone group }\end{array}$ & $\begin{array}{l}\text { Thirty-one ad- } \\
\text { verse events } \\
\text { above grade } 1 \\
\text { were reported } \\
\text { with no signifi- } \\
\text { cant difference in } \\
\text { the two groups }\end{array}$ \\
\hline H.C Williams & 2017 & 253 & 52 weeks & $\begin{array}{l}\text { A pragmatic, } \\
\text { multicenter, } \\
\text { parallel-group } \\
\text { randomized } \\
\text { controlled trial }\end{array}$ & $\begin{array}{l}\text { Doxycycline vs } \\
\text { Prednisolone }\end{array}$ & $\begin{array}{l}\text {-The proportion of } \\
\text { patients with three or } \\
\text { fewer significant } \\
\text { blisters at } 6 \text { weeks } \\
\text {-The proportion of } \\
\text { patients with grade } 3 \\
\text { to } 5 \text { adverse events } \\
\text { at } 52 \text { weeks }\end{array}$ & $\begin{array}{l}\text { Three treatment- } \\
\text { rellated deaths in } \\
\text { the doxycycline } \\
\text { group versus } \\
\text { eleven in the } \\
\text { prednisolone } \\
\text { group }\end{array}$ & $\begin{array}{l}\text { Significant higher } \\
\text { adverse events of } \\
\text { grades } 3 \text { to } 5 \text { for } \\
\text { the prednisolone } \\
\text { group }(36 \%) \\
\text { compared to the } \\
\text { doxycycline } \\
\text { group }(18 \%)\end{array}$ \\
\hline M Amagai & 2016 & 56 & 57 days & $\begin{array}{l}\text { Multicenter, } \\
\text { randomized, } \\
\text { placebo- } \\
\text { controlled, dou- } \\
\text { ble-blind trial }\end{array}$ & $\begin{array}{l}\text { Intravenous } \\
\text { immunoglobulin } \\
\text { (IVIG) }\end{array}$ & $\begin{array}{l}\text { Disease activity } \\
\text { score on day } 15\end{array}$ & Not reported & $\begin{array}{l}\text { No significant } \\
\text { difference was } \\
\text { observed between } \\
\text { the IVIG and } \\
\text { placebo groups } \\
\text { regarding adverse } \\
\text { drug reactions }\end{array}$ \\
\hline
\end{tabular}




Methylprednisolone and azathioprine versus
methylprednisolone and dapsone

Within dermatology units of nine German and Austrian university hospitals, this multicenter and randomized clinical trial was undertaken on BP patients (21). The treatment provided to the patients was oral methylprednisolone (0.5 $\mathrm{mg} / \mathrm{kg}$ per day) along with azathioprine 1.5-2.5 $\mathrm{mg} / \mathrm{kg}$ daily $(\mathrm{n}=27)$ or dapsone $1.5 \mathrm{mg} / \mathrm{kg}$ daily $(\mathrm{n}=27)$. The period up till the complete tapering of methylprednisolone was considered as the primary outcome. Methylprednisolone was discontinued in eight patients, five patients on azathioprine group versus three patients on the dapsone group, following a median duration of 251 and 81 days, respectively.

Low values of corticosteroid median cumulative dose were observed in the dapsone (1.92 g) as compared to the azathioprine $(2.65 \mathrm{~g})$ group; however, with the reference of statistical significance, the difference was negative $(p=0.060)$. In azathioprine and dapsone groups, the average duration till the entire discontinuation of novel blisters was 89 and 42 days respectively $(p=0.261)$. In the postobservational duration of 12 months, $70 \%$ of patients were completely remitted on the treatment with azathioprine whereas $65 \%$ of patients on the treatment with dapsone $(p=0.752)$. During this stage of observation, five patients were completely remitted (four individuals from the dapsone group in comparison with one from the azathioprine group) after the end of the treatment.

Relapse was the novel formation of blisters while reducing the corticosteroid treatment and was observed in 4 patients $(8 \%)$ (2 patients on azathioprine versus 2 on dapsone).

Totally, 31 adverse events (18 in the azathioprine group versus 13 in the dapsone group) above grade 1 were recorded. During the observation period, there were 3 deaths in azathioprine compared to 1 in the dapsone group. One death in the dapsone group was caused by hepatotoxicity, kidney failure, and cardiac arrhythmia that possibly resulted as a consequence of medication.

\section{Doxycycline versus prednisolone}

Through 54 British and Dutch dermatology specialist clinics, 278 cases of BP were randomly assigned in a multicenter pragmatic randomized controlled clinical trial to receive doxycycline (200 $\mathrm{mg}$ daily) $(\mathrm{n}=132)$ or prednisolone $(0.5 \mathrm{mg} / \mathrm{kg}$ daily) $(\mathrm{n}=121)$ as initial treatments $(22)$. In order to receive the treatment with doxycycline or with prednisolone for 6 weeks, participants were randomly assigned. Subsequently, to provide proper treatment for normal clinical practice, the investigators were unmasked

In the study, two principal findings were taken intoaccounts such as a percentage of patients with $\leq 3$ remarkable blisters at the period of 6 weeks and the percentage of patients with grade 3 to 5 adverse events at 52 weeks. Investigators used non-inferiority (with an adequate noninferiority margin of 37 percent) and superiority approaches to compare short-term effectiveness and long-term safety respectively. The study findings manifest that $91 \%$ of those initiated to get treatment with prednisolone had $\leq 3$ blisters at week 6 in comparison with $74 \%$ of participants initiated to get doxycycline treatment (adjusted difference 18.6\% [90\% CI 11·1-26·1]). By week 52, prednisolone group participants were at significant risk to have severe treatment-emergent side effects $(36 \%$ versus $18 \%$, adjusted difference $19 \cdot 0 \%(95 \%$ CI $7 \cdot 9-30 \cdot 1, p=0.001)$. At this time point, there were three treatment-emergent fatalities in the participants treated with doxycycline, whereas 11 fatalities were in the participants treated with prednisolone.

The ratio of participants obtained successful treatment ( $\geq 3$ blisters and no treatment adjustments) at 3 (56\% versus $81 \%), 6$ (54\% versus $85 \%), 13$ (59\% versus $75 \%)$, and $52(41 \%$ versus $51 \%)$ weeks was lower in the doxycycline group versus the prednisolone group. The relapse rate was considered as more than 3 blisters in patients with successful treatment at 6 weeks. The relapse rate was similar in the two treatment groups $(32 \%$ in the doxycycline group versus $36 \%$ in the group exposed to prednisolone with having a corrected difference of $2.1 \%$ [90\% CI -8.312.5]). No distinction has been observed among the two arms in terms of dermatology life quality index (DLQI) and EQOL-5 dimension. Although, post-adjustment of baseline DLQI noted a considerable minor difference in DLQI progress in the severity of disease, age of participants, and Karnofsky score.

Among the prednisolone group, $73 \%$ of participants (which is a high percentage) compared to the doxycycline group (46\%) experienced complete cessation of blisters at 6 weeks. Additionally, the proportion of participants with treatment-associated adverse events (96\% versus $86 \%$ ) and all-cause mortality ( $89 \%$ versus $83 \%$ ) at 52 weeks was greater in the group treated with prednisolone versus the doxycycline group.

\section{Intravenous immunoglobulin (IVIG)}

In Japan, this polycentric, randomly assigned, placebocontrolled, double-blind study was performed in 53 healthcare bodies (24). Patients who had been treated with steroids at a dose of $0.4 \mathrm{mg} / \mathrm{kg}$ daily and did not show any symptomatic improvement included in the investigation. In order to receive human $\operatorname{IgG}(400 \mathrm{mg} / \mathrm{kg}$ per day) $(n=29)$ or placebo (physiological saline) $(n=27)$ for five successive days, the participants were randomly distributed. The efficacy of treatment was evaluated by disease activity score (DAS). On the $15^{\text {th }}$ day, the primary outcome of the investigation was defined as the DAS. The findings of the investigation showed that DAS 15 was lower in the IVIG group $(19.8 \pm 22.2)$ than that in the placebo group (32.3 $\pm 31.5, \mathrm{p}=0.089)$.

Additionally, the IVIG group demonstrated lower scores of DAS in all observation points by day 57 . In patients with severe disease (a DAS score of 40 or more before the study), a considerable difference was noted among both groups with respect to values of DAS on days 8,15 , and 22. Additionally, at all stages of observation, lower values of Japanese BP score and anti-BP180 antibody titer were found in the IVIG group as compared to the values in the placebo group.

There was not any case with severe adverse drug reactions (ADRs) in the two groupis, and no significant differ- 
ence was noted among the two groups regarding the incidence of ADRs. Investigators in the study did not report the relapse and mortality rate of the participants.

\section{Discussion}

We conducted an up-to-date systematic review of treatments for BP on randomized controlled trials published after 2010. In the systematic review, overall, three studies were included which consists up of 363 participants.

The study by Sticherling et al. compared methylprednisolone plus azathioprine versus methylprednisolone plus dapsone (21). It was the first controlled randomized clinical trial that assessed the role of dapsone in the treatment of BP. However, previously a number of noninterventional studies have been published on the use of this drug for the treatment of BP (24-26). The results of the study demonstrated that patients who were treated with dapsone could decrease their systemic corticosteroids faster compared to those on azathioprine. Consequently, the cumulative corticosteroid dose and the number of days on corticosteroids were lower in dapsone-treated patients; although, the differences were not significant. While treating BP, several clinical trials have been investigated the role of various medications in combination with oral steroids (27-29). Beissert et al., in a study, compared oral methylprednisolone plus azathioprine with oral methylprednisolone plus mycophenolate mofetil (27). It was found by investigators that both drugs were equally potent while treating BP. According to the results of the study, no significant difference was observed among the two groups with reference to mean duration of complete remission and cumulative dose of corticosteroids. Although, lower liver toxicity was demonstrated in the mycophenolate mofetil group. In contrast to these findings, the results of a study by Guillaume et al. showed no improvement in disease control by using azathioprine or plasma exchange as adjuvants to corticosteroids (28). Furthermore, Kirtschig et al. in the systematic assessment of interventions for BP, concluded that there is not enough evidence on the effectiveness of the addition of plasma exchange or immunosuppressive drugs such as mycophenolate mofetil or azathioprine to prednisolone or prednisone (20). More RCTs according to the comprehensive analytic statement on clinical outcomes and scoring in BP are required to explore the role of immunosuppressive drugs or plasma exchange in combination with corticosteroids in BP therapy (30)

Tetracyclines have received increasing attention for the treatment of BP as steroid-sparing agents with antiinflammatory and neuroprotective features. Tetracycline's effectiveness while treating BP was investigated in a small RCT published in 1994 with inconclusive results (31). Williams et al. performed a multicenter, pragmatic, parallel-group clinical trial to examine whether the initiation of the treatment with tetracyclines provides short-term control of blisters compared to corticosteroids (22). Although it has been shown that the combination treatment with tetracycline and nicotinamide is possibly effective for BP patients (20), Williams et al. did not combine doxycycline with nicotinamide to assess the efficacy of the antibiotic compared to oral steroids in a clear manner (32). The results of the study confirmed that doxycycline was noninferior to prednisolone as an initial treatment. Whereas the medication was safer in the long-term compared to prednisolone. It seems necessary to assess the role of tetracyclines as a long-term steroid-sparing agent in the treatment of BP patients who have received a short course of corticosteroids. It is supposed that this treatment is associated with a faster remission of BP with a lower incidence of long-term undesirable negative outcomes.

It has been reported that IVIG is a safe and efficient treatment for autoimmune and systemic inflammatory diseases (33). Several case reports and series have indicated that IVIG is a beneficial alternative for the treatment of BP patients who are unable to receive conventional treatment options (34-36). Amagai et al. investigated the therapeutic effect of IVIG when used in higher dosages in non-responsive patients to steroids in a multicenter, randomized, placebo-controlled, double-blind trial (23). The results of the study revealed that IVIG possibly attains the potential to act as a potent agent for patients who become resistant to steroid therapy. However, it is recommended that future investigations examine the long-term effect of IVIG in large randomized clinical trials.

\section{Conclusion}

The results of the present systematic review indicated that dapsone could be used as adjuvant therapy in the treatment of BP with a relatively low mortality rate. Doxycycline as initial treatment was not subordinate to conventional treatment done with oral corticosteroids for acute regulation of blisters but it can be used in combination with corticosteroids regarding its long-term safety. IVIG is possibly a convenient medical therapy for patients who are resistant to steroid therapy. Further large blinded RCTs are required to explore the efficiency and safety of various immunosuppressive drugs and tetracyclines for the treatment of this disease.

\section{Acknowledgment}

We would like to express our gratitude to Isfahan University of Medical Sciences Vice Chancellor for Research, Education, and Research for approving this project.

\section{Conflict of Interests}

The authors declare that they have no competing interests.

\section{References}

1. Bağcı IS, Horváth ON, Ruzicka T, Sárdy M. Bullous pemphigoid. Autoimmun Rev. 2017 Mar 8.

2. Vassileva S. Drug-Induced Pemphigoid: Bullous and Cicatricial. Clin Dermatol. 1998 Jun 30;16(3):379-87.

3. Mul VE, van Geest AJ, Pijls-Johaninesma MC, Theys J, Verschueren TA, Jager JJ, et al. Radiation-induced bullous pemphigoid: a systematic review of an unusual radiation side effect. Radiother Oncol. 2007 Jan 31;82(1):5-9.

4. Nguyen T, Kwan JM, Ahmed AR. Relationship between radiation therapy and bullous pemphigoid. Dermatology. 2014;229(2):88-96.

5. Lai YC, Yew YW, Lambert WC. Bullous pemphigoid and its association with neurological diseases: a systematic review and metaanalysis. J Eur Acad Dermatol Venereol. 2016 Sep 1. 
6. Bertram F, Bröcker EB, Zillikens D, Schmidt E. Prospective analysis of the incidence of autoimmune bullous disorders in Lower Franconia, Germany. J Dtsch Dermatol Ges. 2009 May 1;7(5):434-9.

7. Langan SM, Smeeth L, Hubbard R, Fleming KM, Smith CJ, West J. Bullous pemphigoid and pemphigus vulgaris-incidence and mortality in the UK: population based cohort study. BMJ. 2008 Jul 9;337: a180.

8. Joly P, Baricault S, Sparsa A, Bernard P, Bédane C, Duvert-Lehembre $\mathrm{S}$, et al. Incidence and mortality of bullous pemphigoid in France. $\mathrm{J}$ Invest Dermatol. 2012 Aug 31;132(8):1998-2004.

9. Baican A, Baican C, Chiriac G, Chiriac MT, Macovei V, Zillikens D, et al. Pemphigus vulgaris is the most common autoimmune bullous disease in Northwestern Romania. Int J Dermatol. 2010 Jul 1;49(7):768-74

10. Marazza G, Pham HC, Schärer L, Pedrazzetti PP, Hunziker T, Trüeb $\mathrm{RM}$, et al. Incidence of bullous pemphigoid and pemphigus in Switzerland: a 2-year prospective study. Br J Dermatol. 2009 Oct $1 ; 161(4): 861-8$

11. Junga M, Kippesb W, Messer G, Zillikens D, Rzany B. Increased risk of bullous pemphigoid in male and very old patients: a population-based study on incidence. J Am Acad Dermatol. 1999 Aug 31;41(2):266-8.

12. Di Zenzo G, Marazza G, Borradori L. Bullous pemphigoid: physiopathology, clinical features and management. Adv Dermatol. 2007 Dec 31; 23:257-88.

13. Lamb PM, Abell E, Tharp M, Frye R, Deng JS. Prodromal bullous pemphigoid. Int J Dermatol. 2006 Mar 1;45(3):209-14.

14. Di Zenzo G, Della Torre R, Zambruno G, Borradori L. Bullous pemphigoid: from the clinic to the bench. Clin Dermatol. 2012 Feb 29;30(1):3-16.

15. Schmidt E, Zillikens D. Pemphigoid diseases. Lancet. 2013 Feb 1;381(9863):320-32.

16. Bernard P, Antonicelli F. Bullous Pemphigoid: A Review of its Diagnosis, Associations and Treatment. Am J Clin Dermatol. 2017 Feb 28:1-6.

17. Venning VA, Taghipour K, Mohd Mustapa MF, Highet AS, Kirtschig G. British Association of Dermatologists' guidelines for the management of bullous pemphigoid 2012. Br J Dermatol. 2012 Dec 1;167(6):1200-14.

18. Eming R, Sticherling M, Hofmann SC, Hunzelmann N, Kern JS Kramer $\mathrm{H}$, et al. S2k guidelines for the treatment of pemphigus vulgaris/foliaceus and bullous pemphigoid. J Dtsch Dermatol Ges. 2015 Aug 1;13(8):833-44.

19. Feliciani C, Joly P, Jonkman MF, Zambruno G, Zillikens D, Ioannides D, et al. Management of bullous pemphigoid: the European Dermatology Forum consensus in collaboration with the European Academy of Dermatology and Venereology. Br J Dermatol. 2015 Apr $1 ; 172(4): 867-77$.

20. Kirtschig G, Middleton P, Bennett C, Murrell DF, Wojnarowska F, Khumalo NP.Interventions for bullous pemphigoid. Cochrane Database Syst Rev. 2010;(10).

21. Sticherling M, Franke A, Aberer E, Gläser R, Hertl M, Pfeiffer C, et al. An open, multicenter, randomized clinical study in patients with bullous pemphigoid comparing methylprednisolone and azathioprine with methylprednisolone and dapsone. Br J Dermatol. 2017 Nov 1.

22. Williams HC, Wojnarowska F, Kirtschig G, Mason J, Godec TR, Schmidt E, et al. Doxycycline versus prednisolone as an initial treatment strategy for bullous pemphigoid: a pragmatic, noninferiority, randomised controlled trial. Lancet. $2017 \mathrm{Apr}$ 22;389(10079):1630-8.

23. Amagai M, Ikeda S, Hashimoto T, Mizuashi M, Fujisawa A, Ihn H, et al. A randomized double-blind trial of intravenous immunoglobulin for bullous pemphigoid. J Dermatol Sci. 2017 Feb 1;85(2):77-84.

24. Gürcan HM, Ahmed AR. Efficacy of dapsone in the treatment of pemphigus and pemphigoid. Am J Clin Dermatol. 2009 Dec 1;10(6):383-96.

25. Maggio MC, Corsello G, Prinzi E, Cimaz R. Systemic Lupus Erythematosus and Bullous Pemphigoid with Dramatic Response to Dapsone. Am J Case Rep. 2017; 18:317.

26. Schmidt E, Kraensel R, Goebeler M, Sinkgraven R, Brocker EB, Rzany B, et al. Treatment of bullous pemphigoid with dapsone, methylprednisolone, and topical clobetasol propionate: a retrospective study of 62 cases. Cutis. 2005 Sep 1;76(3):205.

27. Beissert S, Werfel T, Frieling U, Böhm M, Sticherling M, Stadler R, et al. A comparison of oral methylprednisolone plus azathioprine or mycophenolate mofetil for the treatment of bullous pemphigoid. Arch Dermatol. 2007 Dec 1;143(12):1536-42.

28. Guillaume JC, Vaillant L, Bernard P, Picard C, Prost C, Labeille B, et al. Controlled trial of azathioprine and plasma exchange in addition to prednisolone in the treatment of bullous pemphigoid. Arch Dermatol. 1993 Jan 1;129(1):49-53.

29. Burton JL, Harman RR, Peachey RD, Warin RP. Azathioprine plus prednisone in treatment of pemphigoid. $\mathrm{Br}$ Med J. 1978 Oct 28;2(6146):1190-1

30. Daniel BS, Murrell DF, Werth VP. Definitions and outcome measures for bullous pemphigoid: Recommendations by an international panel of experts. J Am Acad Dermatol. 2012 May $1 ; 53: 12$.

31. Fivenson DP, Breneman DL, Riosen GB, Hersh CS, Cardone S, Mutasim D. Nicotinamide and tetracycline therapy of bullous pemphigoid. Arch Dermatol. 1994 Jun 1;130(6):753-8.

32. Chalmers JR, Wojnarowska F, Kirtschig G, Nunn AJ, Bratton DJ, Mason $\mathrm{J}$, et al. A randomized controlled trial to compare the safety and effectiveness of doxycycline (200 $\mathrm{mg}$ daily) with oral prednisolone $(0.5 \mathrm{mg} \mathrm{kg}-1$ daily) for initial treatment of bullous pemphigoid: a protocol for the Bullous Pemphigoid Steroids and Tetracyclines (BLISTER) Trial. Br J Dermatol. 2015;173:227-234.

33. Gelfand EW. Intravenous immune globulin in autoimmune and inflammatory diseases. N Engl J Med. 2012 Nov 22;367(21):2015-25.

34. Ahmed AR. Intravenous immunoglobulin therapy for patients with bullous pemphigoid unresponsive to conventional immunosuppressive treatment. J Am Acad Dermatol. 2001 Dec 1;45(6):825-35.

35. Gaitanis G, Alexis I, Pelidou SH, Gazi IF, Kyritsis AP, Elisaf MS, et al. High-dose intravenous immunoglobulin in the treatment of adult patients with bullous pemphigoid. Eur J Dermatol. 2012 May $1 ; 22(3): 363-9$

36. Tuchinda P, Ritchie S, Gaspari AA. Bullous pemphigoid treated with intravenous immunoglobulin. Cutis. 2014 May;93(5):264-8 